\title{
EDITORIAL
}

\section{Which Suture Material?}

Corneal or corneoscleral sutures were not used in routine cataract surgery until shortly before the second world war. In fact, in the 1965 edition of his surgical textbook, Stallard stated that 'there is a growing trend of opinion, at least among some of the less conservative eye surgeons, that a corneoscleral suture is an important and purposeful essential in cataract extraction both for the intracapsular and extracapsular operation'. Silk was of course the material of choice at that time and Seymour Philps in 1950 in his own surgical textbook held the view that 'no trouble whatever arises from buried silk provided that the operator's technique is foolproof'.

Perhaps we are now more familiar with and more critical of the long term effects of buried silk. On the other hand, when one considers how the improvement in suture materials has benefited routine cataract surgery it is surprising that few clinical trials have been published to demonstrate the relative efficiency of different types of suture and different suture materials. It could be that there is undue confidence in personal experience for this particular aspect of the operation.

In this edition of 'Eye', which incorporates a number of the papers and posters that were presented at the 1990 Annual Oxford Congress, Acheson and Lyons raise questions about monofilament nylon. They find that $8 \%$ of their patients have developed symptoms relating to the degradation of this widely used material. An important finding is that most of the problems seem to arise more than a year after surgery and include simple mechanical discomfort, corneal abscess formation, corneal vascularisation, filamentary keratitis, purulent and giant papillary conjunctivitis.

In the latest edition of Stallard's surgical textbook, Roper Hall (1990) gives a definition of the perfect suture material; 'it should handle comfortably and naturally, the tissue reaction should be minimal, and it should not favour bacterial growth. The breaking strain should be high, knots should hold securely without fraying and the material should be easy to sterilise. It should have no electrolytic, allergenic or carcinogenic action. Finally the suture material should be absorbed after it has finished serving its function'.

Although the use of the fine monofilament suture in association with a corneal section has undoubtedly produced a new generation of white eyes and contented people, the need to bring those involved back for suture removal remains a not insignificant economic burden as well as a personal disadvantage to the patient. Perhaps the introduction of an inert but absorbable corneal suture will be the next breakthrough in cataract surgery.

N. R. Galloway

Master, Oxford Ophthalmological Congress 